Communication

\title{
Is LiI a Potential Dopant Candidate to Enhance the Thermoelectric Performance in Sb-Free GeTe Systems? A Prelusive Study
}

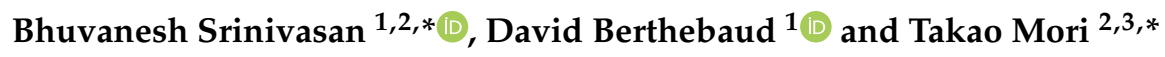 \\ 1 CNRS-Saint Gobain-NIMS, UMI 3629, Laboratory for Innovative Key Materials and Structures (LINK), \\ National Institute for Materials Science (NIMS), Tsukuba 305-0044, Japan; David.BERTHEBAUD@cnrs.fr \\ 2 Center for Functional Sensor \& Actuator (CFSN) \& WPI Center for Materials \\ Nanoarchitechtonics (WPI-MANA), National Institute for Materials Science (NIMS), \\ Tsukuba 305-0044, Japan \\ 3 Graduate School of Pure and Applied Sciences, University of Tsukuba, Tsukuba 305-8671, Japan \\ * Correspondence: SRINIVASAN.Bhuvanesh@nims.go.jp (B.S.); MORI.Takao@nims.go.jp (T.M.)
}

Received: 29 November 2019; Accepted: 30 January 2020; Published: 3 February 2020

\begin{abstract}
As a workable substitute for toxic PbTe-based thermoelectrics, GeTe-based materials are emanating as reliable alternatives. To assess the suitability of LiI as a dopant in thermoelectric GeTe, a prelusive study of thermoelectric properties of $\mathrm{GeTe}_{1-\mathrm{x}} \mathrm{LiI}_{\mathrm{x}}(x=0-0.02)$ alloys processed by Spark Plasma Sintering (SPS) are presented in this short communication. A maximum thermoelectric figure of merit, $z T \sim 1.2$, was attained at $773 \mathrm{~K}$ for $2 \mathrm{~mol} \%$ LiI-doped GeTe composition, thanks to the combined benefits of a noted reduction in the thermal conductivity and a marginally improved power factor. The scattering of heat carrying phonons due to the presumable formation of Li-induced "pseudo-vacancies" and nano-precipitates contributed to the conspicuous suppression of lattice thermal conductivity, and consequently boosted the $z T$ of the $\mathrm{Sb}$-free $(\mathrm{GeTe})_{0.98}(\mathrm{LiI})_{0.02}$ sample when compared to that of pristine GeTe and Sb-rich $(\mathrm{GeTe})_{\mathbf{x}}\left(\mathrm{LiSbTe}_{2}\right)_{2}$ compounds that were reported earlier.
\end{abstract}

Keywords: thermoelectrics; GeTe; LiI as dopant; enhanced power factor; suppressed thermal transport

\section{Introduction}

Thermoelectric (TE) materials and devices have gained limelight due to their ability to reversibly convert waste heat into useful electricity, especially for energy harvesting applications [1-3]. The efficiency of a TE material is quantified by a dimensionless figure of merit, $z T=S^{2} \sigma T / \kappa$, where $\sigma$, $S, T$ and $\kappa$ are the electrical conductivity, Seebeck coefficient, absolute temperature and total thermal conductivity (which constitute both the electronic part, $\kappa_{\mathrm{e}}$, and the lattice part, $\kappa_{\text {latt }}$ ), respectively. These transport properties are highly interlinked and there is a greater challenge in decoupling the electrical and thermal transport parameters [4]. To take on these challenges, an array of novel concepts and approaches have been developed and implemented by the thermoelectric community, such as the concepts of band engineering [5,6], introducing nano-scale features [7,8] and discoveries of novel materials [9-13]. Among those state-of-the-art TE materials, the widely studied lead tellurides are limited by their high toxicity for any commercial application, in spite of their high $z T$ [14-18]. Of late, GeTe-based materials have emerged as viable alternatives, as they have proven to exhibit higher TE performance $(z T>1)$, if optimally alloyed/doped with appropriate elements [19]. Such strategies have been effectively adopted on several classes of GeTe-based materials to improve their electrical transport properties (i.e., the power factor, $S^{2} \sigma$ ) by the convergence of electronic band valleys $[20,21]$ or by the introduction of resonance states [22,23], and/or to suppress their thermal transport properties by nanostructuring [24]. GeTe undergoes a second-order ferroelectric structural transition from 
rhombohedral to cubic symmetry at around $700 \mathrm{~K}$ [19]. This structural transition holds a key in tuning the TE properties of GeTe. In cubic (c) GeTe, there are two valence bands with a small energy offset, whereas there are several sub-valence bands separated by a large energy offset in the case of rhombohedral (r) GeTe [25]. Therefore, the total number of degenerate valleys in c-GeTe is larger than that of $\mathrm{r}-\mathrm{GeTe}$, which will result in a higher total density of states effective mass $\left(\mathrm{m}^{*}\right)$ without affecting much the mobility, thus resulting in an improved TE performance, as illustrated in the case of In-Sb codoped GeTe [26].

The presented communication tries to explore the suitability of LiI as a dopant for improving the TE performance of GeTe. Our studies on the TE properties of the $(\mathrm{GeTe})_{1-\mathrm{x}}(\mathrm{LiI})_{\mathrm{X}}$ system was motivated by a previous report on the $p$-type $(\mathrm{GeTe})_{\mathbf{x}}\left(\mathrm{LiSbTe}_{2}\right)_{2}$ bulk materials, where a strong suppression of $\kappa_{\text {latt }}$ and a slightly improved $z T \sim 1$ at $723 \mathrm{~K}$ was reported [27]. It is well established that Sb doping in GeTe helps in improving the band degeneracy and thus ultimately in a better TE performance $[19,26]$. However a large amount/heavy doping of $\mathrm{Sb}(\sim 8-10 \mathrm{~mol} \%)$ is essential for achieving the favorable TE properties [21]. There is no real harm in doping Sb into GeTe, and this strategy has become increasingly incremental although not many reports exists on new strategies to enhance $z T$ in GeTe without employing $\mathrm{Sb}$. Moreover, in almost all cases where $\mathrm{Sb}$ was doped into $\mathrm{GeTe}$, there was a severe impact on the electrical conductivity $[19,21,26]$. Therefore, a critical challenge remains in achieving higher TE performance in the Sb-free GeTe-based systems. This work is one such attempt in exploring the Sb-free GeTe-based thermoelectric compounds. Improvising on that work on $(\mathrm{GeTe})_{x}\left(\mathrm{LiSbTe}_{2}\right)_{2}$ materials [27], where they attribute the lower thermal transport to the probable "pseudo-vacancy" caused by $\mathrm{Li}$, herein we try to explore the thermoelectric transport properties of $\mathrm{Sb}$-free $(\mathrm{GeTe})_{1-\mathrm{x}}(\mathrm{LiI})_{\mathrm{x}}$ solid-state solutions and compare the performance of these Sb-free compounds with that of pristine GeTe and with the previously reported $\mathrm{Sb}$-rich $(\mathrm{GeTe})_{\mathbf{x}}\left(\mathrm{LiSbTe}_{2}\right)_{2}$ system [27].

\section{Materials and Methods}

The vacuum-sealed tube melt processing route was used to synthesize the samples of $(\mathrm{GeTe})_{1-\mathrm{x}}(\mathrm{LiI})_{\mathrm{x}}(x=0-0.02)$. The powders of the crushed ingots were consolidated by Spark Plasma Sintering, SPS (FCT Systeme $\mathrm{GmbH}$ ), at $773 \mathrm{~K}$ for $5 \mathrm{~min}$ (holding time) under an axial pressure of approx. $60 \mathrm{MPa}$. Powder X-ray diffraction patterns were recorded at room temperature in the $2 \theta$ range $10-90^{\circ}$ with a step size of $0.026^{\circ}$ and a scan per step of $400 \mathrm{~s}$ using a PANalytical X'Pert Pro diffractometer ( $\mathrm{Cu}$ K-L $\mathrm{L}_{2,3}$ radiation, PIXcel 1D detector). The Hall measurements were carried on samples of dimensions $\sim 5 \times 5 \times 2 \mathrm{~mm}^{3}$ using a four-point probe setup (Van der Pauw method), where a fixed magnetic field of $0.112 \mathrm{~T}$ and DC current of $15 \mathrm{~mA}$ was applied. The electrical conductivity and Seebeck coefficients were measured simultaneously from room temperature to $773 \mathrm{~K}$ on samples of dimension $\sim 10 \times 2 \times 2 \mathrm{~mm}^{3}$ using a commercial instrument (LSR-3, Linseis Inc.) in a He atmosphere. Temperature-dependent thermal diffusivity, $D$, was measured on disc shaped samples of dimension $\sim 10 \mathrm{~mm}$ diameter $\times 2 \mathrm{~mm}$ thickness using the laser flash diffusivity method in a Netzsch LFA-457. The heat capacity, $C_{\mathrm{p}}$, was derived using the Dulong-Petit relation, $C_{\mathrm{p}}=3 R / M(R$ is the gas constant and $M$ is the molar mass). The total thermal conductivity was obtained from the equation $\kappa=D C_{\mathrm{p}} \rho$, where $\rho$ is the density of the sample measured using Archimedes' principle. The uncertainty in the results for the values of electrical and thermal transport properties was $\sim 5 \%$ and $\sim 7 \%$, respectively, and for the overall $z T$ it was $\sim 12 \%$ [28]. Error bars are not shown in the figures to increase readability.

\section{Results and Discussion}

The sharp reflections noticed from the X-ray diffraction $(\mathrm{XRD})$ patterns for $(\mathrm{GeTe})_{1-\mathrm{x}}(\mathrm{LiI})_{\mathrm{x}}$ $(x=0-0.02)$ stipulate the phases to be crystalline in nature (Figure 1). The major reflections in both doped and undoped samples could be indexed to the rhombohedral (space group $-R 3 m$ ) GeTe phase (PDF\# 00-047-1079). The double reflections, i.e., (0 24 ) and (2 2 0), in the range of $2 \theta$ values between $41^{\circ}$ and $44^{\circ}$, further confirms the presence of the rhombohedral phase. The secondary phase 
(Ge-rich) was also present, albeit in a minor proportion, and is in agreement with the previously reported studies $[21,23,29,30]$.

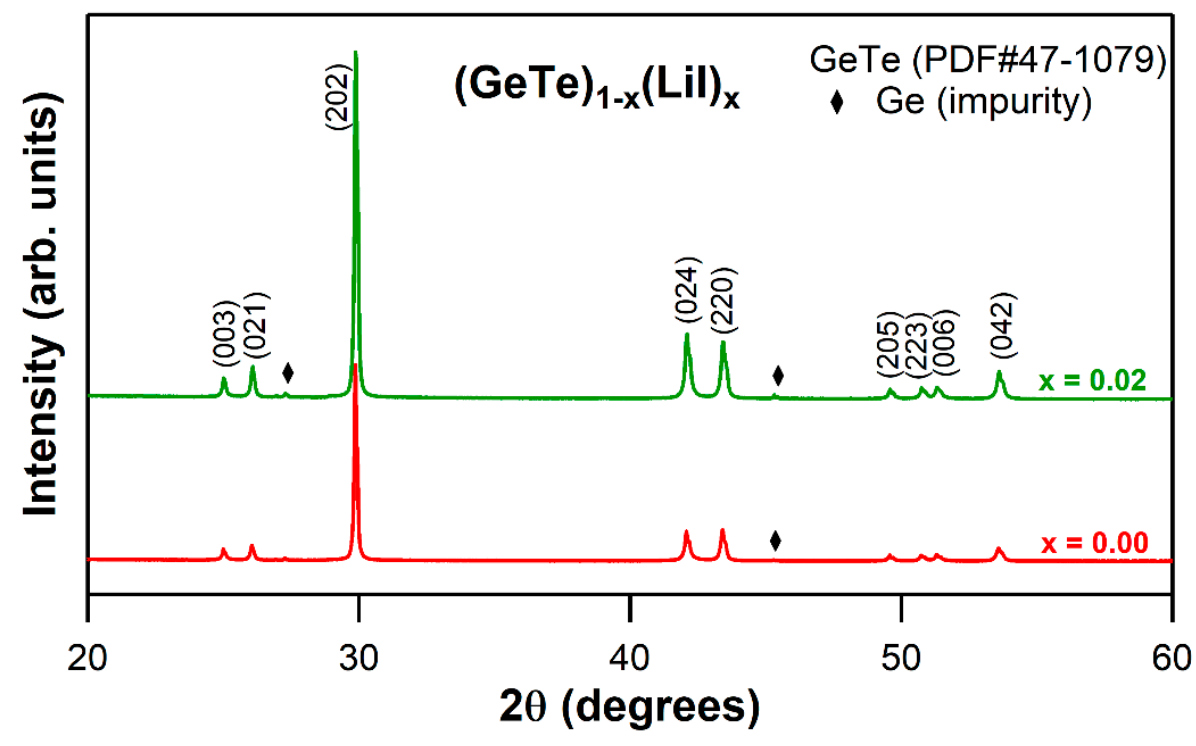

Figure 1. XRD patterns for $(\mathrm{GeTe})_{1-\mathrm{x}}(\mathrm{LiI})_{\mathrm{X}}(x=0-0.02)$ samples.

Results from Hall measurements indicated not much variation in the carrier concentration $(n)$ and mobility $(\mu)$, as the pristine GeTe exhibited $n \sim 9.08 \times 10^{20} \mathrm{~cm}^{-3}$ and $\mu \sim 57 \mathrm{~cm}^{2} \mathrm{~V}^{-1} \mathrm{~s}^{-1}$, while the $2 \mathrm{~mol} \%$ LiI-doped GeTe exhibited $n \sim 9.3 \times 10^{20} \mathrm{~cm}^{-3}$ and $\mu \sim 54 \mathrm{~cm}^{2} \mathrm{~V}^{-1} \mathrm{~s}^{-1}$. As the Hall voltage was positive in the $(\mathrm{GeTe})_{1-\mathrm{x}}(\mathrm{LiI})_{\mathrm{X}}(x=0-0.02)$ system, holes are the dominant charge carriers ( $p$-type). With increasing temperature, the electrical conductivity of the samples slumped (Figure 2a), suggesting a degenerate semi-conducting behavior. The Seebeck coefficient was found to be positive (Figure $2 \mathrm{~b}$ ), thus confirming the $p$-type behavior in the LiI-doped GeTe, which is in line with the Hall measurement results.

Doping LiI into GeTe marginally enhanced the electrical conductivity, which could probably be due to the LiI-driven higher ionicity and the Seebeck coefficient remained more or less the same as the pristine GeTe. This led to a small but significant improvement in the power factor $\left(P . F=S^{2} \sigma\right)$ at elevated temperatures (Figure 2c). In a previously reported Li-Sb codoped study [27], it was postulated that the higher ionicity of Li helped in optimizing the electrical transport properties in those compounds. Considering the close similarities between these material systems, the assumption that LiI-driven ionicity as a cause for improved electrical transport properties in this case seems to hold good. LiI-doping into GeTe markedly decreased the total thermal conductivity (Figure 2d), thanks to the suppressed lattice contribution (Figure 2e). In the case of pristine GeTe, it is well established that the formation energy of the Ge vacancy is quite low, and it is the easily formed intrinsic defect [31,32]. It is reported that $\mathrm{Li}$ can fill the cation vacancies and is quite light; hence, it can be regarded as a "pseudo-vacancy", as illustrated by Schröder et al. [27]. Employing $\mathrm{Li}^{+}$as a "pseudo-vacancy" might have created a substantial mass difference between the atoms involved, which can potentially disturb the lattice vibrational modes and retard the lattice phononic contribution to the thermal conductivity. Nanostructuring can also be a reason for suppression of lattice contribution, as SPS processing is known to create nano-scale inclusions, defects, dislocations, misfit strains, displacement layers, precipitates and micro/nano-porosity [33-39], all of which, depending on their sizes, are known to scatter phonons of different mean free paths. It can be noted that at around $673 \mathrm{~K}$, there is a change of trend in both electrical and thermal transport properties (for both pristine and LiI-doped GeTe), which is an indication noting the structural transition from the rhombohedral to cubic phase (at $\sim 673 \mathrm{~K}$ ). Lil-doping in GeTe has helped to simultaneously enhance the power factor and suppress the thermal transport. This cumulative effect of marginally enhanced power factor and significantly suppressed thermal 
transport has facilitated the LiI-doped GeTe to exhibit a superior thermoelectric figure of merit, $z T \sim 1.2$ at $773 \mathrm{~K}$ (Figure $2 \mathrm{f}$ ), when compared to the pristine GeTe ( $z T \sim 0.9$ at $773 \mathrm{~K}$ ). It must be noted that the $z T$ $\sim 1.2$ at $773 \mathrm{~K}$ for the $\mathrm{Sb}$-free $(\mathrm{GeTe})_{0.98}(\mathrm{LiI})_{0.02}$ composition that is reported in this work is considerably higher than what was reported in the literature for the Sb-rich $(\mathrm{GeTe})_{x}\left(\mathrm{LiSbTe}_{2}\right)_{2}$ composition $(z T \sim 1$ at $723 \mathrm{~K})$.
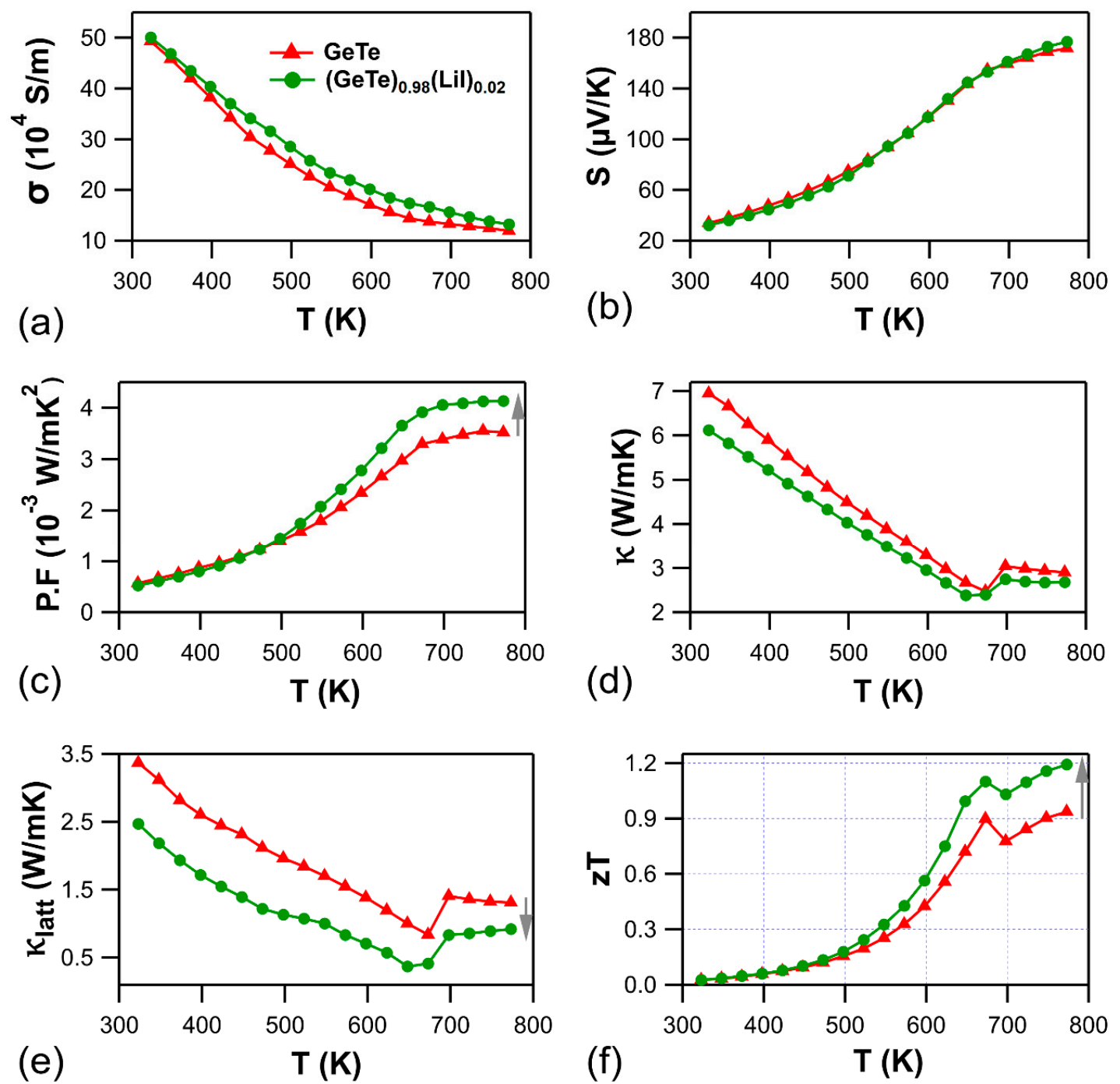

Figure 2. (a) Electrical conductivity, $\sigma$; (b) Seebeck coefficient, $S$; (c) power factor, P.F; (d) total thermal conductivity, $\kappa ;(\mathbf{e})$ lattice contribution to the thermal conductivity, $\kappa_{\text {latt }}$; and (f) thermoelectric figure of merit, $z T$, for the $(\mathrm{GeTe})_{1-\mathrm{x}}(\mathrm{LiI})_{\mathrm{X}}(x=0-0.02)$ compounds.

As such, this communication has exposed LiI-doped GeTe as a potential candidate for mid-temperature range TE module fabrication, if a suitable $n$-type counterpart is figured out. More in-depth analysis and experimentation with the variation of LiI content to optimize the dopant concentration $(x)$ in $(\mathrm{GeTe})_{1-\mathrm{x}}(\mathrm{LiI})_{\mathrm{x}}$ system are to be explored in the near future to investigate if the $z T$ can be pushed up further (say, closer to 1.5 ) with an optimal level of doping and processing conditions.

\section{Conclusion}

Highly dense samples of $(\mathrm{GeTe})_{1-\mathrm{x}}(\mathrm{LiI})_{\mathrm{x}}(x=0-0.02)$ compounds were successfully synthesized via a two-step process (i.e., melt-processing followed by SPS). Substitution of LiI in GeTe was found to contemporaneously enhance the electrical transport and suppress the thermal transport, thus ultimately boosting up the $z T$. The Sb-free sample of the $(\mathrm{GeTe})_{0.98}(\mathrm{LiI})_{0.02}$ composition exhibited an improved $z T$ 
$\sim 1.2$ at $773 \mathrm{~K}$, which is markedly higher than that of pristine GeTe and the Sb-rich $(\mathrm{GeTe})_{\mathrm{x}}\left(\mathrm{LiSbTe}_{2}\right)_{2}$ compounds that were reported earlier, thus opening up new avenues to explore further and optimize these $(\mathrm{GeTe})_{1-\mathrm{x}}(\mathrm{LiI})_{\mathrm{x}}$ compounds for a potential mid-temperature range thermoelectric application.

Author Contributions: B.S. designed and performed the experiments, analyzed the results and wrote the manuscript; project administration, D.B.; funding acquisition, T.M.; all authors contributed to the final manuscript. All authors have read and agreed to the published version of the manuscript.

Funding: This research was initially funded by European Commission's Horizon 2020 research and innovation program under the Marie Skłodowska-Curie grant (GA. 642557, CoACH-ETN), and later by the Japanese Society for the Promotion of Science (JSPS) via postdoctoral fellowship (P19720). Article processing charges were funded by JSPS KAKENHI (19F19720), JST CREST JPMJCR15Q and JPMJCR19Q.

Acknowledgments: Bruno Bureau (Université Rennes 1) and Catherine Boussard-Pledel (CNRS) are thanked for their constant support.

Conflicts of Interest: The authors declare no conflict of interest.

\section{References}

1. Mori, T.; Priya, S. Materials for energy harvesting: At the forefront of a new wave. MRS Bull. 2018, 43, 176-180. [CrossRef]

2. Petsagkourakis, I.; Tybrandt, K.; Crispin, X.; Ohkubo, I.; Satoh, N.; Mori, T. Thermoelectric materials and applications for energy harvesting power generation. Sci. Technol. Adv. Mater. 2018, 19, 836-862. [CrossRef] [PubMed]

3. Srinivasan, B. Novel Chalcogenide Based Glasses, Ceramics and Polycrystalline Materials for Thermoelectric Application. Ph.D. Thesis, Université Rennes 1, Rennes, France, 2018.

4. Chen, Z.; Jian, Z.; Li, W.; Chang, Y.; Ge, B.; Hanus, R.; Yang, J.; Chen, Y.; Huang, M.; Snyder, G.J.; et al. Lattice Dislocations Enhancing Thermoelectric PbTe in Addition to Band Convergence. Adv. Mater. 2017, 29, 1606768. [CrossRef] [PubMed]

5. Pei, Y.; Wang, H.; Snyder, G.J. Band Engineering of Thermoelectric Materials. Adv. Mater. 2012, 24, 6125-6135. [CrossRef] [PubMed]

6. Zhang, Q.; Cao, F.; Liu, W.; Lukas, K.; Yu, B.; Chen, S.; Opeil, C.; Broido, D.; Chen, G.; Ren, Z. Heavy Doping and Band Engineering by Potassium to Improve the Thermoelectric Figure of Merit in p-Type PbTe, PbSe, and $\mathrm{PbTe}_{1-\mathrm{y}} \mathrm{Se}_{\mathrm{y}}$. J. Am. Chem. Soc. 2012, 134, 10031-10038. [CrossRef] [PubMed]

7. Kanatzidis, M.G. Nanostructured Thermoelectrics: The New Paradigm? Chem. Mater. 2010, 22, 648-659. [CrossRef]

8. Chen, Z.-G.; Han, G.; Yang, L.; Cheng, L.; Zou, J. Nanostructured thermoelectric materials: Current research and future challenge. Prog. Nat. Sci. Mater. Int. 2012, 22, 535-549. [CrossRef]

9. Madsen, G.K.H. Automated Search for New Thermoelectric Materials: The Case of LiZnSb. J. Am. Chem. Soc. 2006, 128, 12140-12146. [CrossRef]

10. Sootsman, J.R.; Chung, D.Y.; Kanatzidis, M.G. New and Old Concepts in Thermoelectric Materials. Angew. Chem. Int. Ed. 2009, 48, 8616-8639. [CrossRef]

11. Srinivasan, B.; Cui, S.; Prestipino, C.; Gellé, A.; Boussard-Pledel, C.; Ababou-Girard, S.; Trapananti, A.; Bureau, B.; Di Matteo, S. Possible Mechanism for Hole Conductivity in Cu-As-Te Thermoelectric Glasses: A XANES and EXAFS Study. J. Phys. Chem. C 2017, 121, 14045-14050. [CrossRef]

12. Zhang, T.; Wang, Z.; Srinivasan, B.; Wang, Z.; Zhang, J.; Li, K.; Boussard-Pledel, C.; Troles, J.; Bureau, B.; Wei, L. Ultraflexible Glassy Semiconductor Fibers for Thermal Sensing and Positioning. ACS Appl. Mater. Interfaces 2019, 11, 2441-2447. [CrossRef] [PubMed]

13. Srinivasan, B.; Boussard-Pledel, C.; Dorcet, V.; Samanta, M.; Biswas, K.; Lefèvre, R.; Gascoin, F.; Cheviré, F.; Tricot, S.; Reece, M.; et al. Thermoelectric Properties of Highly-Crystallized Ge-Te-Se Glasses Doped with $\mathrm{Cu} /$ Bi. Materials 2017, 10, 328. [CrossRef] [PubMed]

14. Snyder, G.J.; Toberer, E.S. Complex thermoelectric materials. Nat. Mater. 2008, 7, 105-114. [CrossRef] [PubMed]

15. He, J.; Kanatzidis, M.G.; Dravid, V.P. High performance bulk thermoelectrics via a panoscopic approach. Mater. Today 2013, 16, 166-176. [CrossRef] 
16. Zhao, L.-D.; Dravid, V.P.; Kanatzidis, M.G. The panoscopic approach to high performance thermoelectrics. Energy Environ. Sci. 2013, 7, 251-268. [CrossRef]

17. Srinivasan, B.; Gucci, F.; Boussard-Pledel, C.; Cheviré, F.; Reece, M.J.; Tricot, S.; Calvez, L.; Bureau, B. Enhancement in thermoelectric performance of n-type Pb-deficit Pb-Sb-Te alloys. J. Alloys Compd. 2017, 729, 198-202. [CrossRef]

18. Srinivasan, B.; Fontaine, B.; Gucci, F.; Dorcet, V.; Saunders, T.G.; Yu, M.; Cheviré, F.; Boussard-Pledel, C.; Halet, J.-F.; Gautier, R.; et al. Effect of the Processing Route on the Thermoelectric Performance of Nanostructured $\mathrm{CuPb}_{18} \mathrm{SbTe}_{20}$. Inorg. Chem. 2018, 57, 12976-12986. [CrossRef]

19. Perumal, S.; Roychowdhury, S.; Biswas, K. High performance thermoelectric materials and devices based on GeTe. J. Mater. Chem. C 2016, 4, 7520-7536. [CrossRef]

20. Roychowdhury, S.; Samanta, M.; Perumal, S.; Biswas, K. Germanium Chalcogenide Thermoelectrics: Electronic Structure Modulation and Low Lattice Thermal Conductivity. Chem. Mater. 2018, 30, 5799-5813. [CrossRef]

21. Srinivasan, B.; Gellé, A.; Gucci, F.; Boussard-Pledel, C.; Fontaine, B.; Gautier, R.; Halet, J.-F.; Reece, M.J.; Bureau, B. Realizing a stable high thermoelectric zT $\sim 2$ over a broad temperature range in $\mathrm{Ge}_{1-\mathrm{x}-\mathrm{y}} \mathrm{Ga}_{\mathrm{x}} \mathrm{Sb}_{\mathrm{y}} \mathrm{Te}$ via band engineering and hybrid flash-SPS processing. Inorg. Chem. Front. 2019, 6, 63-73. [CrossRef]

22. Wu, L.; Li, X.; Wang, S.; Zhang, T.; Yang, J.; Zhang, W.; Chen, L.; Yang, J. Resonant level-induced high thermoelectric response in indium-doped GeTe. NPG Asia Mater. 2017, 9, e343. [CrossRef]

23. Srinivasan, B.; Boussard-Pledel, C.; Bureau, B. Thermoelectric performance of codoped (Bi, In)-GeTe and (Ag, In, Sb)-SnTe materials processed by Spark Plasma Sintering. Mater. Lett. 2018, 230, 191-194. [CrossRef]

24. Perumal, S.; Roychowdhury, S.; Biswas, K. Reduction of thermal conductivity through nanostructuring enhances the thermoelectric figure of merit in $\mathrm{Ge}_{1-x} \mathrm{Bi}_{x} \mathrm{Te}$. Inorg. Chem. Front. 2016, 3, 125-132. [CrossRef]

25. Li, J.; Chen, Z.; Zhang, X.; Sun, Y.; Yang, J.; Pei, Y. Electronic origin of the high thermoelectric performance of GeTe among the p-type group IV monotellurides. NPG Asia Mater. 2017, 9, e353. [CrossRef]

26. Hong, M.; Chen, Z.-G.; Yang, L.; Zou, Y.-C.; Dargusch, M.S.; Wang, H.; Zou, J. Realizing zT of 2.3 in $\mathrm{Ge}_{1-\mathrm{x}-\mathrm{y}} \mathrm{Sb}_{\mathrm{x}} \mathrm{In}_{\mathrm{y}} \mathrm{Te}$ via Reducing the Phase-Transition Temperature and Introducing Resonant Energy Doping. Adv. Mater. 2018, 30, 1705942. [CrossRef]

27. Schröder, T.; Schwarzmüller, S.; Stiewe, C.; de Boor, J.; Hölzel, M.; Oeckler, O. The Solid Solution Series $(\mathrm{GeTe})_{\mathrm{x}}\left(\mathrm{LiSbTe}_{2}\right)_{2}(1 \leq \mathrm{x} \leq 11)$ and the Thermoelectric Properties of $(\mathrm{GeTe})_{11}\left(\mathrm{LiSbTe}_{2}\right)_{2}$. Inorg. Chem. 2013, 52, 11288-11294. [CrossRef]

28. Simon, J.; Guélou, G.; Srinivasan, B.; Berthebaud, D.; Mori, T.; Maignan, A. Exploring the thermoelectric behavior of spark plasma sintered $\mathrm{Fe}_{7-x} \mathrm{Co}_{x} \mathrm{~S}_{8}$ compounds. J. Alloys Compd. 2020, 819, 152999. [CrossRef]

29. Srinivasan, B.; Gautier, R.; Gucci, F.; Fontaine, B.; Halet, J.-F.; Cheviré, F.; Boussard-Pledel, C.; Reece, M.J.; Bureau, B. Impact of Coinage Metal Insertion on the Thermoelectric Properties of GeTe Solid-State Solutions. J. Phys. Chem. C 2018, 122, 227-235. [CrossRef]

30. Srinivasan, B.; Gellé, A.; Halet, J.-F.; Boussard-Pledel, C.; Bureau, B. Detrimental Effects of Doping Al and Ba on the Thermoelectric Performance of GeTe. Materials 2018, 11, 2237. [CrossRef]

31. Levin, E.M. Effects of Ge substitution in GeTe by Ag or Sb on the Seebeck coefficient and carrier concentration derived from ${ }^{125}$ Te NMR. Phys. Rev. B 2016, 93, 045209. [CrossRef]

32. Edwards, A.H.; Pineda, A.C.; Schultz, P.A.; Martin, M.G.; Thompson, A.P.; Hjalmarson, H.P.; Umrigar, C.J. Electronic structure of intrinsic defects in crystalline germanium telluride. Phys. Rev. B 2006, 73, 045210. [CrossRef]

33. Hong, M.; Wang, Y.; Feng, T.; Sun, Q.; Xu, S.; Matsumura, S.; Pantelides, S.T.; Zou, J.; Chen, Z.-G. Strong Phonon-Phonon Interactions Securing Extraordinary Thermoelectric $\mathrm{Ge}_{1-\mathrm{x}} \mathrm{Sb}_{\mathrm{x}} \mathrm{Te}$ with Zn-Alloying-Induced Band Alignment. J. Am. Chem. Soc. 2019, 141, 1742-1748. [CrossRef] [PubMed]

34. Zheng, Z.; Su, X.; Deng, R.; Stoumpos, C.; Xie, H.; Liu, W.; Yan, Y.; Hao, S.; Uher, C.; Wolverton, C.; et al. Rhombohedral to Cubic Conversion of GeTe via MnTe Alloying Leads to Ultralow Thermal Conductivity, Electronic Band Convergence, and High Thermoelectric Performance. J. Am. Chem. Soc. 2018, 140, 2673-2686. [CrossRef] [PubMed]

35. Perumal, S.; Samanta, M.; Ghosh, T.; Shenoy, U.S.; Bohra, A.K.; Bhattacharya, S.; Singh, A.; Waghmare, U.V.; Biswas, K. Realization of High Thermoelectric Figure of Merit in GeTe by Complementary Co-doping of Bi and In. Joule 2019, 3, 2565-2580. [CrossRef] 
36. Bayikadi, K.S.; Sankar, R.; Wu, C.T.; Xia, C.; Chen, Y.; Chen, L.-C.; Chen, K.-H.; Chou, F.-C. Enhanced thermoelectric performance of GeTe through in situ microdomain and Ge-vacancy control. J. Mater. Chem. A 2019, 7, 15181-15189. [CrossRef]

37. Biswas, K.; He, J.; Blum, I.D.; Wu, C.-I.; Hogan, T.P.; Seidman, D.N.; Dravid, V.P.; Kanatzidis, M.G. High-performance bulk thermoelectrics with all-scale hierarchical architectures. Nature 2012, 489, 414-418. [CrossRef]

38. Grasso, S.; Kim, E.-Y.; Saunders, T.; Yu, M.; Tudball, A.; Choi, S.-H.; Reece, M. Ultra-Rapid Crystal Growth of Textured SiC Using Flash Spark Plasma Sintering Route. Cryst. Growth Design 2016, 16, 2317-2321. [CrossRef]

39. Qian Zhang, Y.L. Increased thermoelectric performance by $\mathrm{Cl}$ doping in nanostructured $\mathrm{AgPb}_{18} \mathrm{SbSe}_{20-\mathrm{x}} \mathrm{Cl}_{\mathrm{x}}$. Nano Energy 2013, 2, 1121-1127. [CrossRef]

(C) 2020 by the authors. Licensee MDPI, Basel, Switzerland. This article is an open access article distributed under the terms and conditions of the Creative Commons Attribution (CC BY) license (http://creativecommons.org/licenses/by/4.0/). 